\title{
$\nabla$ Animation Therapy for Improving Social Interaction
in Children with Autism Spectrum Disorder
}

\section{IJCRR}

Section: Healthcare ISI Impact Factor (2019-20): 1.628

IC Value (2019): 90.81 $\operatorname{SJIF}(2020)=7.893$

(c) (7) (8)

Copyright@IJCRR

\section{Senthil $\mathbf{V}^{1}$, Ancy $\mathbf{R}^{2}$, Christopher AV ${ }^{3}$}

\begin{abstract}
'King Saud Bin Abdulaziz University for Health Sciences, Department of Occupational Therapy, Al Hasa-Kingdom of Saudi Arabia; 'Pediatric Occupational Therapist, Shumua AL Amal for Special Education and Rehabilitation, Dammam, Kingdom of Saudi Arabia; ${ }^{3} V i c e$ Deanship of Quality and Development, College of Medicine, Imam Abdulrahman Bin Faisal University, P.O. Box 1982, Dammam 31441, Saudi Arabia.
\end{abstract}

\section{ABSTRACT}

Introduction: Animation is about creativity, movement, and imagination. It offers the opportunity to bring an object, drawing or person to life. The creative process of animation has been adapted to provide a clinically effective framework to complement evidence-based therapeutic practice. Using simple techniques, this approach has been designed to facilitate motivation with difficult to reach clients. With the flexibility to work with verbal, non-verbal materials animation enables the service user to express thoughts and feelings using visual, tactile, and auditory techniques.

Aim: To identify high functioning autism children using the High-Functioning Autism Spectrum Screening Questionnaire (ASSQ). To review the effect of animation therapy for improving social skills, communication, and self-confidence in an experimental group of youngsters with an autism spectrum disorder.

Method: The study was done on 40 subjects, 20 in the control group and 20 in the experimental group. The screening for top functioning autism clients was done using the High-Functioning Autism Spectrum Screening Questionnaire (ASSQ). The pre-test and post-test were done using the Gilliam Autism Rating Scale (GARS-2). The scores of both groups were compared to find out the effectiveness.

Result: Statistical analysis shows there is a statistically important distinction in the social interaction of youngsters.

Conclusion: This study concludes that animation medical care is simpler in up social interaction in kids with syndrome Autism Spectrum Disorder.

Key Words: Animation Therapy, Social Interaction, Autism Spectrum Disorder, Obsessive Compulsive disorder, Attention-deficit/hyperactivity disorder, High-functioning autism spectrum disorder

\section{INTRODUCTION}

Chemical imbalance is a complex formative incapacity that regularly shows during the initial three years of life. This neurological problem influences the typical working of the mind, affecting advancement in zones of social cooperation, correspondence, and conduct. The activity is about inventiveness, development, and creative mind. ${ }^{1}$ It offers the occasion to bring an article, attracting or individual to live. The capacity of liveliness cycles to speak to change and change which be a unique picture seems, by all accounts, to be significant in the restorative cycle and this is being investigated further effectively and essentially. By doing liveliness - the individual, family or gathering effectively take an interest utilizing an active methodology, with the movement cycle for helpful purposes custom fitted to their novel necessities. ${ }^{2,3}$

\section{Animation Therapy}

Animation can be used as a strong yet sensitive tool in a therapeutic context to help people to tell their stories and to express emotions, thoughts, and feelings. It enables people to directly and non -directly explore issues and needs therapeutically in a visual, tactile and auditory way. Techniques can be used that extends beyond words and generates different ways of looking at something relevant in a person's life or therapeutic process.

Activity can be utilized as a solid yet touchy instrument in a remedial setting to help individuals to recount their accounts

\section{Corresponding Author:}

Christopher AV, Vice Deanship for Quality and Development, College of Medicine, Imam Abdulrahman Bin Faisal University, King Fahd Hospital of the University, P.O. Box 1982, Dammam 31441, Saudi Arabia. Tel: +966-581963915; E-mail: christopheramalraj@gmail.com and cadoss@iau.edu.sa

ISSN: 2231-2196 (Print)

Received: 30.11 .2020
ISSN: 0975-5241 (Online)

Revised: 18.01 .2020
Accepted: 12.03 .2021
Published: 22.06 .2021 
and to communicate feelings, contemplations, and emotions. It empowers individuals to straightforwardly and non - legitimately investigate issues and needs restoratively in a visual, material, and hear-able way. Procedures can be utilized that reaches out incredible and produces various perspectives that are applicable in an individual's life or restorative cycle. ${ }^{1}$

\section{Why Occupational Therapy and Animation?}

Animation in its nature involves complex processes that can be graded to help clients achieve optimum occupational performance levels with the right therapeutic facilitation. If the core of occupational therapy is the therapeutic use of an activity to enable independence, optimum -performance and healing, then the benefits of offering animation as a treatment could be as follows: It crosses generation gaps. Animation can be accessible for the very young children \& elderly alike if they consider it to be a purposeful activity. ${ }^{1}$

Animation can be incorporated into skills-based training (for example social skills, anxiety and anger control programs) taught on an individual basis or with groups. Animation is essentially a group process in nature with many different roles uniting to contribute to the end product. The therapist can, however, adopt the techniques for individual sessions according to the person's unique interests. The need to work with other people (either directly or non-directly) makes it useful for exploring relationships. Parent-child attachments can be explored through the animation process, building relationships through child-led exploration. Therapy can also be targeted for specific conditions by breaking the activity down into its parts, increasing self-esteem and self-worth and enable therapeutic risk-taking. ${ }^{1}$

Within an institutional setting, for example, forensic psychiatry; youth offending institutes; children requiring long periods of hospitalization; animation enables the client to project into a world of imagination to offer hope and prepare for change. What appears to be unique about the use of animation as an activity in therapy is the range of creative possibilities and activities that can be explored. This can be subsequently tailored into a program of activity and discovery which is specifically motivating for young people lead by their interests, pitched at their level of function. ${ }^{1}$

Activity in its tendency includes complex cycles that can be evaluated to assist customers with accomplishing ideal word related execution levels with the correct restorative help. If the centre of word related treatment is the remedial utilization of an action to empower autonomy, ideal execution, and mending, at that point the advantages of offering movement as a treatment could be as per the following: It crosses age holes. Movement can be open for little youngsters and older the same on the off chance that they believe it to be an intentional action. Liveliness can be consolidated into abilitiesbased preparing (for instance social aptitudes, tension, and outrage control programs) educated on an individual premise or with gatherings. ${ }^{1}$

\section{Literature Review}

Helen RM did a study on activity with explicit conditions: From her underlying perceptions in clinical work, she found that the accompanying conditions might be helped to utilize movement strategies: Obsessive-enthusiastic turmoil (OCD) - the advisor has used acquainting the youngster with the ideas of OCD as a beast with the aims of externalizing feelings into liveliness. ${ }^{1}$

Ulin work exhibited a steady part of video demonstrating for Autism spectrum disorder (ASD) understudies. By utilizing video displaying using companions, it can significantly build ASD understudies' presentation in social commencements and close shortfalls in peer play. It likewise profited the ordinary training understudies by tolerating ASD understudies in a typical social talk inside the comprehensive setting. ${ }^{2}$

Massaro directed an investigation on improving the jargon of kids with hearing misfortune: The objective of this examination was to test the adequacy of a language PC energized coach, for showing new jargon things to youngsters with a consultation misfortune. Eight understudies with hearing misfortune, between the ages of 6 and 10, were tried and prepared for around 20-30 minutes per day, 2 days every week for around 10 weeks on three classifications of eight words each. ${ }^{3}$ Mayer study shows that activity can improve human learning-particularly when the objective is to advance profound comprehension in five out of five test correlations, understudies performed better on critical thinking move tests when they contemplated liveliness and portrayal without as opposed to with unessential words, video, or sounds. ${ }^{4}$

Sunny did an investigation on setting out to expand information about the clinical introduction, weakness level, related issues, and screening/recognizable proof of young ladies coming to centres with non-determined social as well as consideration deficiencies. An inside and out contextual investigation of six young ladies introducing to clinicians with social deficiencies had demonstrated that they all met measures for mental imbalance. The clinical evaluations were completely performed by the creator. ${ }^{5}$ Karim propose that more open emergency clinics are needed to receive increasingly more electronic health record (EHR) and EHR functionalities. An occasional appraisal of EHR status should be acted notwithstanding or a piece of an empowering/authorizing approaches that can fundamentally build the pace of appropriation of EHR frameworks. ${ }^{6}$

Marja result shows to assess the legitimacy of the ASSQ. The members of this investigation were drawn from two progressing examines concerning more advanced young- 
sters with a chemical imbalance. ${ }^{7}$ Maj study evaluated the dispersion of medically introverted highlights in an all-out populace of kids 7-9 years old and investigated the effect old enough, sex, source, and cooperation inclination on indication report. Instructor and parent types of the Autism Spectrum Screening Questionnaire (ASSQ) were utilized, an allout populace investigation of 9430 youngsters matured 7-9 years. Finished educator structures were returned for $97 \%$ and parent structures for $71 \%$ of the kids. ${ }^{8}$

High scorers were characterized by the Autism Spectrum Screening Questionnaire (ASSQ) approval concentrate by Stephen conveyance of ASSQ scores was discovered to be practically consistent. Of the youngsters with both an educator and a parent structure, $2.1 \%$ were characterized as high scorers. Young men scored higher and guardians revealed more manifestations, especially in young ladies. ${ }^{9}$

Yan article shows that the Autism Spectrum Screening Scale (ASSQ) is a 27-thing agenda initially created in Sweden and distributed in English for evaluations of Asperger condition and other advanced ASDs. The utility in Chinese-talking populaces was at this point to be set up. ${ }^{10}$

The Gilliam Autism Rating Scale (GARS) was created as a generally simple, modest guide in the reconnaissance and finding of chemical imbalance. This examination analyzed the legitimacy of the GARS when utilized with an example of 119 youngsters with severe DSM-IV conclusions of chemical imbalance, learned from both clinical and exploration settings. The GARS reliably thought little of the probability that mentally unbalanced youngsters in this example would be delegated having a chemical imbalance. ${ }^{11}$ The Autism Spectrum Screening Questionnaire (ASSQ) has recently been appeared to have great screening properties in clinical settings. This investigation utilized the ASSQ to screen a complete populace of 7-9-year-olds $(\mathrm{N}=9430)$ for ASD in the Bergen Child Study. ${ }^{12}$

The reason for this investigation was to investigate the legitimacy and dependability of the Turkish Version of the Gilliam Autism Rating Scale-2 (TV-GARS-2). Members included 436 youngsters determined to have a chemical imbalance (331 male and 105 females. Information was likewise gathered from people determined to have a scholarly handicap, with hearing debilitation, and from regularly creating kids to analyze segregation legitimacy of the TV-GARS-2. ${ }^{13}$

Qualitative contrasts in social communication style exist inside the chemical imbalance range. In this investigation, we inspected whether these distinctions are related to (1) the seriousness of medically introverted indications and comorbid problematic conduct issues, (2) the kid's psycho-social wellbeing, and (3) chief working and point of view taking aptitudes. The social association style of 156 youngsters and youths (6-19 years) with advanced chemical imbalance range problem (HFASD) was resolved. ${ }^{14}$ This examination investigation the real relational working existing with recognizable accomplices in regular daily existence. ${ }^{15}$

The mental strengthening of medical attendants can upgrade their consistency and support in security measures. This paper adds to the current security writing and nursing researcher by exhibiting the impact of mental strengthening on wellbeing execution. Seen the executive's duty to security as an arbiter gives bits of knowledge to pioneers. Wellbeing policymakers and security directors (i.e., disease control officials) should keep their medical caretakers engaged mentally and know about their genuine promise to wellbeing to upgrade work environment wellbeing of attendants. ${ }^{16}$

\section{METHODOLOGY}

\section{Participants and procedures}

The investigation was led in KMCH College at the Department of word related treatment, Coimbatore for about a month and a half during December 2018. An example size of $(\mathrm{n}=40)$ youngsters with ASD were taken, who were separated into 2 gatherings exploratory $(n=20)$ and control $(n=20)$ gathering. Advantageous the arbitrary inspecting procedure was utilized to choose the investigation subjects. Inclusion criteria: Children who are diagnosed with ASD by a psychiatrist or a paediatrician, Children of age group 6-18 years, Children of both sexes, Exclusion criteria: Children with Attention-deficit/hyperactivity disorder (ADHD), Children with visual or hearing impairments, children with apraxia.

\section{Tools Used:}

The High-Functioning Autism Spectrum Screening Questionnaire (ASSQ), A screening poll for Asperger condition and other advanced mental imbalance range issues in young kids. The 27 things were appraised on a 3-point scale $(0,1$, and 2), 0 -ordinariness, 1 -some irregularity, and 2-unequivocal anomaly. Eleven things tap subjects with respect to the social association, 6 cover correspondence issues, and 5 allude to confined and dull conduct. The leftover five things grasp engine ungainliness and other related manifestations including engine and vocal spasms. Absolute scores range from 0 to $54 .{ }^{9}$

\section{Gilliam Autism Rating Scale-2 ${ }^{\text {nd }}$ Edition}

The Gilliam Autism Rating Scale-Second Edition (GARS-2) tt is a standard referred to as an instrument that mirrors the conceptualizations of chemical imbalance per the Diagnostic and Statistical Manual of Mental Disorders by Gilliam. The GARS-2 uses a normalized score alluded to as the Autism Index. Conduct Checklist with 3 sub-scales comprising of Stereotyped Behaviors, Communication, Social Interaction. The scoring design is 0-Never noticed, 1-rarely noticed, 2-in 
some cases noticed, and 3-habitually noticed, Concurrent legitimacy was investigated by associating GARS-2 scores with the Autism. ${ }^{17}$

\section{Reliability:}

The inside consistency of each subscale just as the GARS-2 test was resolved using Cronbach's coefficient alpha. Coefficients uncover that each subtest, just as the complete Autism Index, is profoundly reliable and subsequently adequate for adding to the determination of mental imbalance. To decide scale soundness, 40 people with mental imbalance were tried twice with the GARS-2 over a 1-week time frame. Test-retest coefficients for each subscale and the all-out score are all past the .01 noteworthiness level, and age-rectified coefficients range from .70 to .90 . Connection coefficients were revised for the limitation in range. The outcomes show a high relationship for the Autism Index.

\section{Data Collection Procedure:}

Assent was taken from the top of the organizations and guardians to lead the investigation. The reason for the examination was disclosed to the guardians before the initiation of the investigation. The youngsters were similarly gathered into two as test and control gathering (20 in each gathering). Pretest was accomplished for the 40 kids utilizing the GARS-2 scale to know the seriousness of mental imbalance. The Autism Spectrum Screening Questionnaire (ASSQ) is utilized to screen out advanced mental imbalance customers.

An acquaintance was given with the customers about liveliness treatment and an affinity building meeting was directed. To begin with, they were shown movement procedures for the initial 15 minutes and afterwards for 30 minutes they needed to make models utilizing dirt, polished papers, garments and so forth At that point, a set is made utilizing these models and different materials like diagram papers and crepe papers. Pictures of models are caught and placed into the PC and saw. They are educated to make flipbooks utilizing papers and paints, These meetings were was proceeded for 1 and off months, Posttest was finished utilizing GARS2 scale following one and off a long time for both test and control gathering, Using factual examination the adequacy of activity treatment was finished.

SESSION 1: An introduction was given to the clients about animation therapy and a rapport building session was conducted. SESSION 2: First they were taught animation techniques for the first 15 minutes and then for 30 minutes they had to make models using clay, glossy papers, clothes etc. SESSION 3: Then a set is made using these models and other materials like chart papers and crepe papers. SESSION 4: Images of models are captured and put into the computer and viewed. SESSION 5: They are taught to make flipbooks using papers and paints, (1)These sessions were was continued for 1 month, (2) Post-test was done using GARS 2 scale after one month for both experimental and control group, (3) Using statistical analysis the effectiveness of animation therapy was done

\section{DATA ANALYSIS AND RESULTS}

A test of 40 subjects took an interest in the investigation out of which 20 were in charge gathering and 20 in test gathering. They were analyzed as a "chemical imbalance range problem" utilizing the ASSQ and GARS-2. Information acquired was factually dissected utilizing the Statistical Package of Social Sciences (SPSS) $23^{\text {rd }}$ Edition.

Table 1 Shows the ASSQ Scores among the Control group and Experimental group. All participants having High Functioning Autism in this study. Table 2 shows that there is no factually critical distinction between the pretest scores of control and trial bunch among the Stereotype conduct, Communication and Social collaboration. There is no factually critical distinction between the posttest scores of control and test bunch among the Stereotype conduct and Communication. Be that as it may, there is a measurably huge contrast between posttest scores of control and trial bunch among the Social association. Table 3 show that there is a statistically significant difference in the pre and post-test scores for stereotype behaviour, communication, and social interaction in the control and experimental groups.

\section{DISCUSSION}

In this test study, 40 subjects were included out of which 20 subjects were assembled under trial gathering and the other 20 levelled out gathering. Both gatherings bear similar consideration and prohibition standards. At first, all the subjects were analyzed by directing GARS-2, after which the ASSQ was managed for screening out the "advanced mental imbalance" kids. This investigation uncovers that the exploratory gathering who went through movement treatment demonstrated improvement in the GARS-2 scores after treatment (table3). This discovery associate with the investigation done by Helen Rachel Mason, in which test bunch indicated improvement in social abilities, self-articulation, and correspondence. ${ }^{1}$

Every segment of GARS-2 i.e., generalization conduct, correspondence and social collaboration demonstrated changes, in test bunch customers. This discovering corresponds with the examination done by Ravit in movement treatment which detailed enhancements in correspondence. ${ }^{18}$ This likewise associates to another investigation done by Ann which announced upgrades in social collaboration and self-articulation and a decrease in generalization conduct. The generali- 
zation conduct and correspondence segment have decreased by 2-3 scores. The investigation further uncovers that the control bunch additionally indicated improvement in the GARS-2 scores (table-3). ${ }^{19}$

The test bunch went through movement treatment, recommending that the improvement made by test bunch is for the most part because of activity treatment, which was led for one and off months (5 days of the week) with a span of 45 minutes for each meeting. The pretest scores of exploratory and control bunch were looked at which indicated no distinction among the two and post-test scores of test and control bunch show that there is a distinction in the scores of control and trial gathering, the measurable investigation uncovers that the distinction in scores isn't at a critical level. In this examination the term of treatment was short and subsequently, further investigations with an all-encompassing span of treatment would be useful. Generally, the examination clarifies that activity treatment is compelling in improving social connection and correspondence in mental imbalanced kids.

\section{CONCLUSION}

The investigation reasoned that movement treatment is powerful in improving social cooperation and correspondence and decreasing generalization conduct in chemical imbalance youngsters.

Impediments: The term of study was for a brief period, just a single part of activity treatment was utilized, just a single part of the GARS-2 scale was engaged, and a Limited number of test size was utilized. Proposals: Duration of the investigation should be broadened, the two parts of liveliness treatment can be utilized, All the three segments of GARS-2 scale can be centred around, Therapy can be actualized for different conditions, for example, OCD, Asperger disorder, a Large number of test size can be utilized.

Acknowledgement: All professionals do their work by themselves. Although they can be as prolific or as adept in their respective fields, they will still need assistance one way or another. For instance, writing a body of work takes a lot of research. They often depend on their assistants or subordinates to gather information about the subject matter. Aside from the research people, other individuals can also receive credit for their contributions to the writer's work.

\section{Conflict of interest: Nil}

\section{Source of funding: Nil}

Author Contributions: Mr. Senthil did the Online study and Review of the writing assortment, Ancy did assortment information on the web and cause to dominate sheet for the SPSS information examination design, Dr Christopher Done the measurable investigation utilizing SPSS programming, results, diary configurations and tables, Dr Palanivel did the technique part, Dr Mohsina has done the references and arrangement.

\section{REFERENCES}

1. Mason H. Dare to dream: The use of animation in occupational therapy. Ment Heal Occup Ther. 2009 Nov;14(3):111-5. http:// animationtherapy.co.uk/Research/Dare-to-Dream-The-use-ofanimation-in-occupational-therapy

2. Ulin A. Video modelling: play skills for students with autism spectrum disorder via peers. Graduate Research Papers, 2014; 240. https://scholarworks.uni.edu/grp/240

3. Massaro DW, Light J. Improving the vocabulary of children with hearing loss. Work. 2004 Jul 1;831:459-2330. https://www. learntechlib.org/p/104871/

4. Mayer RE, Moreno R. Animation as an aid to multimedia learning. Edu Psych Rev. 2002 Mar;14(1):87-99. https://doi. org/10.1023/A:1013184611077

5. Kopp S. Girls with social and/or attention impairments. 2010 Sep 3. https:/gupea.ub.gu.se/bitstream/2077/23134/1/gupea_2077_23134_1.pdf.

6. Jabăli AK. Electronic health records functionalities in Saudi Arabia: Obstacles and major challenges. Glob J Heal Sci. 2018;10(4):1-50. http://www.ccsenet.org/journal/index.php/ gjhs/article/view/73101

7. Mattila ML, Jessika K, Kuusikko S, Kielinen M, Linna SL, Ebeling H, et al., When does the Autism Spectrum Screening Questionnaire (ASSQ) predict autism spectrum disorders in primary school-aged children. Eur Child Adoles Psych. 2009 Aug;18(8):499-509. https://link.springer.com/article/10.1007/ s00787-009-0044-5

8. Posted MB, Lundervold AJ, Gillberg C. Autistic features in a total population of 7-9-year-old children assessed by the ASSQ (Autism Spectrum Screening Questionnaire). J Child Psych Psych. 2006 Feb;47(2):167-75. https://pubmed.ncbi.nlm.nih. gov/16423148/

9. Ehlers S, Gillberg C, Wing L. A screening questionnaire for Asperger syndrome and other high-functioning autism spectrum disorders in school-age children. J Aut Devp Dis. 1999 Apr;29(2):129-41. https://link.springer.com/article/10.1023\%2 FA\%3A1023040610384.

10. Guo YQ, Tang Y, Rice C, Lee LC, Wang YF, Cubells JF. Validation of the autism spectrum screening questionnaire, Mandarin Chinese version (CH-ASSQ) in Beijing, China. Autism. 2011 Nov;15(6):713-27. https://pubmed.ncbi.nlm.nih.gov/21690211/.

11. South M, Williams BJ, McMahon WM, Owley T, Filipek PA, Shernoff E, et al., Utility of the Gilliam Autism Rating Scale in research and clinical populations. $\mathrm{J}$ autism and developmental disorders. 2002 Dec;32(6):593-9. https://doi. org/10.1023/A:1021211232023

12. Posserud MB, Lundervold AJ, Gillberg C. Validation of the autism spectrum screening questionnaire in a total population sample. J Aut Devp Dis. 2009 Jan 1;39(1):126-34. https://pubmed. ncbi.nlm.nih.gov/18592364/

13. Diken IH, Diken O, Gilliam JE, Ardic A, Sweeney D. Validity and Reliability of Turkish Version of Gilliam Autism Rating Scale-2: Results of Preliminary Study. Int J Spe Edu. 2012;27(2):207-15. https://eric.ed.gov/?id=EJ982874

14. Scheeren AM, Koot HM, Begeer S. Social interaction style of children and adolescents with high-functioning autism spectrum disorder. J Aut Develop Dis. 2012 Oct;42(10):2046-55. https:// doi.org/10.1007/s10803-012-1451-x 
15. Plumet M, Tardif C. Understanding the functioning of social interaction with autistic children. Emer Comm. 2005; 7:181. http://www.emergingcommunication.com.

16. Al-Bsheish M, bin Mustafa M, Ismail M, Meri A, Dauwed M. Perceived management commitment and psychological empowerment: A study of intensive care unit nurses' safety. Safety Sci. 2019 Oct 1; 118:632-40. https://www.sciencedirect.com/science/article/pii/S0925753518307094?via\%3Dihub

17. Gilliam JE. Gilliam autism rating scale 2nd Edition (GARS2). Austin, TX: ProEd. 2006. https://journals.sagepub.com/ doi/10.1177/0734282908317116
18. Cohen-Mimran R, Sapir S. Rate change detection of frequency modulated signals: developmental trends. J Basic Clin Phys Pharmac. 2011 Sep 1;22(3):65-8. https://www.degruyter.com/ view/journals/jbcpp/22/3/article-p65.xml.

19. Mullen AL, Goyette KA. Aiming high: social and academic correlates of applying to and attending 'reach 'universities. Bri J Soc Educ. 2019 Nov 17;40(8):1072-89.

20. https://www.tandfonline.com/doi/full/10.1080/01425692.2019. 1647090

\section{Table 1: ASSQ Screening Results for Control Group}

\begin{tabular}{llll} 
S. No. & CGS & EGS & Category \\
1 & 22 & 24 & HFA \\
2 & 22 & 22 & HFA \\
3 & 26 & 24 & HFA \\
4 & 25 & 23 & HFA \\
5 & 23 & 22 & HFA \\
6 & 27 & 22 & HFA \\
7 & 20 & 25 & HFA \\
8 & 24 & 23 & HFA \\
9 & 22 & 22 & HFA \\
10 & 24 & 24 & HFA \\
11 & 22 & 24 & HFA \\
12 & 22 & 22 & HFA \\
13 & 26 & 24 & HFA \\
14 & 25 & 23 & HFA \\
15 & 23 & 22 & HFA \\
16 & 27 & 22 & HFA \\
17 & 20 & 25 & HFA \\
18 & 24 & 23 & HFA \\
19 & 22 & 22 & HFA \\
20 & 24 & 24 & HFA \\
\hline
\end{tabular}

CGS - Control Group Scores, EGS - Experimental Group Scores and HFA - High Functioning Autism,

Table 2: Comparison of Pretest Scores, posttest scores of GARS-2 Between Control and Experimental Group

\begin{tabular}{|c|c|c|c|c|}
\hline Pretest & $\begin{array}{c}\text { Control group } \\
\text { Mean } \pm \text { SD }\end{array}$ & $\begin{array}{c}\text { Experimental group } \\
\text { Mean } \pm \text { SD }\end{array}$ & t - Value & p-value \\
\hline Stereotype behavior & $12.5 \pm 0.83$ & $12.4 \pm 0.79$ & 1.560 & $0.907^{\mathrm{ns}}$ \\
\hline Communication & $13.2 \pm 0.93$ & $12.8 \pm 0.87$ & 0.620 & $0.558^{\text {ns }}$ \\
\hline Social interaction & $12.4 \pm 0.81$ & $12.4 \pm 0.80$ & 0.493 & $0.642^{\mathrm{ns}}$ \\
\hline \multicolumn{5}{|l|}{ Posttest } \\
\hline Stereotype behavior & $11.6 \pm 0.75$ & $10.3 \pm 0.68$ & 2.16 & $0.63^{\mathrm{ns}}$ \\
\hline Communication & $12.2 \pm 0.78$ & $11.1 \pm 0.69$ & 1.60 & $0.16^{\mathrm{ns}}$ \\
\hline Social interaction & $11.4 \pm 0.70$ & $5.5 \pm 0.48$ & 11.6 & $0.001^{* * *}$ \\
\hline
\end{tabular}

Ns-Not statistically significance difference at $95 \%(\mathrm{p}>0.05),{ }^{* * *}$ - Statistically significant difference $99.9 \%(\mathrm{p}<0.001)$ 
Table 3: Comparison of Pre and Post Scores of GARS-2 among the Experimental and Control Group

\begin{tabular}{lcccc} 
Control Group & $\begin{array}{c}\text { Pretest } \\
\text { Mean } \pm \text { SD }\end{array}$ & $\begin{array}{c}\text { Posttest } \\
\text { Mean } \pm \text { SD }\end{array}$ & t - Value & p - value \\
Stereotype behavior & $12.5 \pm 0.83$ & $11.6 \pm 0.75$ & 9.00 & $0.001^{* * *}$ \\
Communication & $13.2 \pm 0.93$ & $12.2 \pm 0.78$ & 8.76 & $0.001^{* * *}$ \\
Social interaction & $12.4 \pm 0.81$ & $11.4 \pm 0.70$ & 4.74 & $0.001^{* * *}$ \\
Experimental Group & & & & \\
Stereotype behavior & $12.4 \pm 0.79$ & $10.3 \pm 0.68$ & 11.69 & $0.001^{* * *}$ \\
Communication & $12.8 \pm 0.87$ & $11.1 \pm 0.69$ & 11.12 & $0.001^{* * *}$ \\
Social interaction & $12.4 \pm 0.80$ & $5.5 \pm 0.48$ & 19.41 & $0.001^{* * *}$ \\
\hline
\end{tabular}

***- Statistically significant difference $99.9 \%(\mathrm{p}<0.001)$ 